Jurnal Ilmu Dan Teknologi Kesehatan

Vol 7, No 1, September 2019,

ISSN: 2338-9095 (Print)

ISSN: 2338-9109 (online)

\title{
Pengetahuan Gizi dan Keaktifan Ibu Balita dalam Kunjungan Posyandu Berhubungan dengan Status Gizi Balita
}

\author{
Wahyu Elia Ramadani, Afriyana Siregar, Desri Suryani \\ Poltekkes Kemenkes Bengkulu \\ Email:Wahyue0333@gmail.com
}

\author{
Artikel history \\ Dikirim, Mei $24^{\text {th }}, 2019$ \\ Ditinjau, Apr 24 $4^{\text {th }}, 2019$ \\ Diterima, Sept $5^{\text {th }}, 2019$
}

\begin{abstract}
Children nutritional problem in Indonesia remains as a challenge in health aspect. Several ways that can affect children nutrient status namely; the mothers' knowledge towards nutrition and their activeness in Posyandu. In order to achieve the optimal status of children nutrition, the mothers need to be involved in Posyandu activity so the nutritional status can be monitored. This research aimed to discover the relation between nutrition knowledge and mother's activeness in Posyandu visitation with children nutritional status in Puskesmas Pasar Ikan working area, Bengkulu, in 2019. This research used observational method and cross sectional approach. The technique that was used is quota sampling technique with 92 repondents. Chi square was used as statistic analysis tool. This research showed that 43,5\% of children nutrition in normal status, 2,2\% in critical status, and the last 54,3\% in chronic status. The majority of sample showed a sufficient knowledge about nutrition with 40,2\%. The active respondent with more that 8 visits showed a satisfying numbers with $68,5 \%$, meanwhile the other only acquired 31,5\%. The result of chi square statistic showed that there was a connection between knowledge about nutrition and mothers' activeness in Posyandu visitation with children nutritional status.
\end{abstract}

Keywords: nutritional status; nutrition knowledge; activeness to visit Posyandu

\begin{abstract}
ABSTRAK
Masalah gizi balita masih menjadi tantangan kesehatan bagi Indonesia. Beberapa cara yang dapat mempengaruhi status gizi balita yaitu pengetahuan ibu dan keaktifan ibu ke posyandu. Tingkat pengetahuan gizi ibu kurang dapat mengubah sikap dan prilaku ibu dalam memilih makanan yang di konsumsi balita. Agar tercapainya status gizi balita yang optimal maka ibu yang memiliki anak balita hendaknya aktif dalam kegiatan posyandu. Tujuan Penelitian ini adalah untuk mengetahui hubungan pengetahuan gizi dan keaktifan ibu balita dalam kunjungan posyandu dengan status gizi balita di wilayah kerja Puskesmas Pasar Ikan Kota Bengkulu Tahun 2019. Metode penelitian ini yaitu metode observasional dengan pendekatan penelitian cross sectional. Teknik yang digunakan adalah teknik quota Sampling dengan jumlah sampel 92 responden. Analisis statistik adalah uji chi square. Hasil Penelitian ini menunjukkan bahwa 43,5\% status gizi balita normal, 2,2\% status gizi balita akut dan 54,3\%
\end{abstract}


status gizi balita kronis. Pengetahuan gizi ibu sebagian besar cukup (40,2\%). Responden yang aktif $>8 x$ setahun sebesar $68,5 \%$ dan tidak aktif sebesar $31,5 \%$. Kesimpulan penelitian ini yaitu adanya hubungan antara pengetahuan gizi dan keaktifan ibu balita dalam kunjungan posyandu dengan status gizi balita.

Kata Kunci : Pengetahuan gizi; Keaktifan ibu balita; Status gizi balita

\section{PENDAHULUAN}

Masa yang paling utama bagi seorang balita periode dua tahun pertama kehidupan disebut juga dengan periode emas (Golden age). Pada masa ini merupakan titik kritis bagi pertumbuhan dan perkembangan balita. Kebutuhan zat gizi tidak dapat terpenuhi maka dapat terjadi gangguan gizi di masa tersebut dan akan berdampak pada masa yang akan mendatang (Muklis,dkk 2018). Masalah gizi di Indonesia masih menjadi tantangan kesehatan. Berdasarkan WHO, Data Indonesia tahun 2007-2016 prevalensi stunting $36,4 \%$, wasting $13,5 \%$ dan overweight $11,5 \%$ pada usia dibawah 5 tahun selalu meningkat (Fithria, dkk 2015). Berdasarkan data Provinsi Bengkulu prevalensi tahun 2016-2017 menurut $\mathrm{BB} / \mathrm{U}$ (gizi buruk 1\%, gizi kurang $4,51 \%$ ), menurut $\mathrm{TB} / \mathrm{U}$ (Sangat pendek $1,99 \%$, pendek 4,45\%) menurut $\mathrm{BB} / \mathrm{TB}$ (Sangat kurus 1,4\%) (Kemenkes RI, 2018).

Status Gizi merupakan keadaan di mana tubuh manusia dapat berdampak pada konsumsi makanan dan penggunaan zatzat gizi. Status gizi dibagi menjadi 2 faktor yaitu faktor langsung dan faktor tidak langsung. Asupan makan dan Penyakit Infeksi adalah faktor yang menyebabkan status gizi secara lagsung, sedangkan Pengetahuan ibu tentang gizi, usia penyapihan, berat bayi lahir rendah (BBLR), pemberian makanan terlalu dini, besar keluarga, pola asuh anak, kesehatan lingkungan, serta pelayanan kesehatan adalah faktor yang menyebabkan status gizi secara tidak langsung (UNICEF, 1990). Salah satu yang mempengaruhi status gizi kurang balita adalah pengetahuan ibu tentang gizi (Tantejo, dkk 2014). Pengetahuan gizi merupakan pengetahuan tentang makanan dan zat gizi, makanan dengan zat gizi pada makanan, makanan yang dikonsumsi aman dan tidak menimbulkan penyakit dan cara pengolahan yang baik agar tidak menghilangkan zat gizi pada makanan tersebut. Tingkat pengetahuan ibu yang kurang dapat mempengaruhi sikap dan prilaku ibu dalam memilih makanan yang dikonsumsi oleh balita yang akan menjadi penentu status gizi balita (Watania dkk, 2016). 
Selain itu faktor pelayanan kesehatan (posyandu) juga mempengaruhi status gizi balita seperti keaktifan dalam kunjungan posyandu. Salah satu tujuan posyandu untuk memantau peningkatan status gizi masyarakat terutama anak balita dan ibu hamil. Rendahnya pemahamam keluarga dan masyarakat akan manfaat posyandu akan berakibat tidak maksimalnya pemantauan pertumbuhan balita (Maria, dkk 2017). Keaktifan ibu setiap kegiatan posyandu tentu akan berpengaruh pada keadaan status gizi balita. Cankupan Balita yang ditimbang menggambarkan tingkat motivasi/partisipasi masyarakat dalam memantau pertumbuhan dan perkembangan, serta kesehatan balita di posyandu. Cakupan kunjungan persentase nasional balita yang ditimbang di posyandu sebesar 80\% (Kemenkes, 2013). Keberhasilan posyandu terlihat dari cakupan SKDN dimana (S) merupakan seluruh jumlah balita di wilayah posyandu, (K) jumlah balita yang memiliki KMS, (D) balita yang ditimbang, (N) balita yang berat badannya naik. Pemantauan pertumbuhan balita di suatu wilayah $\mathrm{K} / \mathrm{S}$ cakupan program $>80 \%$ dikatakan baik < $80 \%$ kurang, D/S partisipasi > 80\% dikatakan baik < 80\% kurang, N/D keadaan pertumbuhan balita $>80 \%$ dikatakan baik < 80\% kurang (Legi, dkk. 2015).
Hasil survei awal yang dilakukan diwilayah kerja puskesmas pasar ikan ditemukan data 9 kelurahan dan 15 Posyandu dengan jumlah balita dari usia 059 bulan yaitu 1.127 balita. Dari 10 balita data status gizi interpretasi 3 indikator tersbut adalah $6(60 \%)$ balita kronis, 2 (20\%) balita akut dan 2 (20\%) balita normal. Tingkat pengetahuan ibu yang dikategorikan kurang berjumlah 3 orang (30\%). Dari data puskesmas kunjungan balita tiap bulan yang ditimbang dalam 6 bulan terakhir sebesar 453 balita $(75,5 \%)$ dan dibandingkan dengan cakupan persentase nasional $80 \%$ masih dikategorikan rendah. Tujuan dari penelitian ini adalah untuk mengetahui hubungan antara pengetahuan gizi dan keaktifan ibu balita dalam kunjungan posyandu di Wilayah Kerja Puskesmas Pasar Ikan Kota Bengkulu Tahun 2019.

\section{METODE}

Penelitian ini menggunakan metode observasional dengan pendekatan penelitian cross sectional yaitu observasional atau pengukuran terhadap variabel independen (Pengetahuan Gizi dan Frekuensi Keaktifan Ibu balita dalam kunjungan Posyandu) dan variabel dependen (Status Gizi Balita) yang diukur atau dikumpulkan dalam waktu yang bersamaan. Populasi penelitian seluruh 
balita sebanyak 1.127 balita di Puskesmas Pasar Ikan Kota Bengkulu. Pengambilan sampel secara Non probability sampling dengan teknik quota sampling. Penentuan sampel setiap posyandu digunakan rumus proporsional sampling dan diperoleh sampel sebanyak 92 orang. Penelitian ini dilakukan di 15 posyandu di Wilayah Kerja Puskesmas Pasar Ikan Kota Bengkulu selama 1 bulan dari tanggal 15 Februari - 15 Maret 2019. Teknik pengumpulan data menggunakan data sekunder yang diperoleh dari data dari buku Kartu Menuju Sehat (KMS) atau pencatatan dan pelaporan kunjungan posyandu Puskesmas Pasar Ikan Kota Bengkulu. Alat pengumpulan data berupa kuesioner pengetahuan dan keaktifan. Alat pengukuran status gizi balita menggunakan microtoise dan timbangan digital. Analisis data univariat yaitu analisis yang digunakan terhadap tiap variabel hasil penelitian yang hanya menghasilkan distribusi dan persentase tiap variabel (Notoatdmojo,2010). Analisis data bivariat untuk mengetahui kemaknaan hubungan antara pengetahuan gizi dan keaktifan ibu balita dalam kunjungan posyandu maka dilakukan uji statistik adalah uji chi square $(P<0,05)$.

\section{HASIL DAN PEMBAHASAN}

Tabel 1. Distribusi Frekuensi Gambaran Pengetahuan Gizi

\begin{tabular}{ccc}
\hline Pengetahuan gizi & N & \% \\
\hline Baik & 21 & 22,8 \\
Cukup & 37 & 40,2 \\
Kurang & 34 & 37,0 \\
\hline Jumlah & 92 & 100 \\
\hline
\end{tabular}

Tingkat pengetahuan seseorang dibagi menjadi 3 kategori yaitu baik, cukup, dan kurang. Hasil penelitian ini menunjukkan pengetahuan ibu dengan kategori cukup sebesar $37(40,2 \%)$ yang mempengaruhi status gizi balita dengan interpretasi indikator pertumbuhan. Penelitian ini hampir sama dengan penelitian Tantejo,dkk (2014) diketahui pengetahuan ibu kategori cukup sebesar 36 (37,9\%).
Pada penelitian tersebut menunjukkan bahwa adanya faktor pengetahuan ibu tentang gizi dengan status gizi balita di wilayah kerja Puskesmas XIII Kota Kampar. Penelitian lainnya menurut Sakbaniyah,dkk (2012) di Desa Sumberejo Kecamatan Miranggen Kabupaten Demak menunjukkan hubungan pengetahuan gizi kategori cukup dengan kepatuhan kunjungan balita diketahui sebanyak 44 
responden $(53,0 \%)$. Penelitian Selanjutnya

Siagian,dkk (2015) di Puskesmas

Kelurahan Pancoran Jakarta Selatan menunjukkan pengetahuan ibu dengan status gizi balita diketahui kategori cukup $9(10 \%)$.

Tabel 2. Distribusi Frekuensi Keaktifan Ibu Balita dalam Kunjungan Posyandu

\begin{tabular}{ccc}
\hline Keaktifan & n & \% \\
\hline Aktif $>8$ x/tahun & 63 & 68,5 \\
Tidak Aktif $<8$ x/tahun & 29 & 31,5 \\
\hline Jumlah & 92 & 100 \\
\hline
\end{tabular}

Pada penelitian ini menunjukkan keaktifan ibu balita berkunjung ke posyandu dalam satu tahun dengan status gizi balita diketahui sebesar $63(68,5 \%)$ aktif $>8 x$ setahun dan $29(31,5 \%)$ tidak aktif $<8 \mathrm{x}$ setahun. Penelitian ini sejalan dengan
Mauludi (2018) di Desa Triwung lor Kecamatan Kademangan Probolinggo menunjukkan keaktifan ibu berkunjung ke posyandu dengan status gizi bayi sebanyak $16(30,2 \%)$ dikatakan aktif dan $37(69,8 \%)$ ibu dikatakan tidak aktif.

Tabel 3. Distribusi Frekuensi Status Gizi Balita

\begin{tabular}{ccc}
\hline Status Gizi & n & \% \\
\hline Normal & 40 & 43,5 \\
Akut & 2 & 2,2 \\
Kronis & 50 & 54,3 \\
\hline Jumlah & 92 & 100 \\
\hline
\end{tabular}

Status gizi balita dilakukan menggunakan 3 indikator status gizi yaitu $\mathrm{BB} / \mathrm{U}, \mathrm{TB} / \mathrm{U}$ dan BB/TB. Kemudian dilakukan interpretasi ke 3 indikator masalah gizi tersebut yang digolongkan menjadi 3 kategori yaitu normal, kronis dan akut. Penelitian ini menunjukkan status gizi balita dalam interpetasi indikator pertumbuhan sebagian balita memiliki status gizi normal $40(43,5 \%)$, sedikit yang memiliki status gizi akut $2(2,2 \%)$, dan sebagian besar balita memiliki status gizi kronis $50 \quad(54,3 \%)$. Status gizi ini dipengaruhi oleh faktor pengetahuan gizi dan keaktifan ibu balita dalam kunjungan posyandu. Penelitian ini sejalan dengan penelitian Muklis,dkk (2018) di Desa Ketapang Raya Lombok Timur pada status gizi balita dengan kunjungan ibu menunjukkan status gizi balita dengan status gizi baik sejumlah 68 (79,1\%), balita dengan status gizi kurang berjumlah 
$14(16,3 \%)$ dan status gizi buruk yaitu berjumlah 4(4,7\%). Selain itu sejalan dengan penelitian Lanoh,dkk (2015) bahwa hubungan pemanfaatan posyandu dengan status gizi menunjukkan sebagian besar 37 balita $(64,9 \%)$ memiliki status gizi baik dan 20 balita $(35,1 \%)$ memiliki status gizi kurang. Analisa bivariat hubungan pengetahuan gizi dengan status gizi balita yang ditinjau dari interpretasi 3 indikator masalah gizi di Wilayah Kerja Puskesmas Pasar Ikan Kota Bengkulu tahun 2019 dilakukan dengan uji statistik Chi-square yaitu uji Pearson Chi-square dengan tabel $3 \times 3$ dan $p$-value $(0,05)$. Hasil analisis tersebut dapat dilihat pada tabel di bawah ini:

Tabel 4. Hubungan pengetahuan gizi dengan status gizi balita

\begin{tabular}{lccccc}
\hline \multirow{2}{*}{$\begin{array}{c}\text { Variabel (pengetahuan } \\
\text { gizi) }\end{array}$} & \multicolumn{3}{c}{ Status Gizi Balita } & \multirow{2}{*}{ Total } & \multirow{2}{*}{ p-value } \\
\cline { 2 - 4 } (Interpretasi Indikator Pertumbuhan) & Normal & Akut & Kronis & & \\
\hline Baik & 13 & 0 & 8 & 21 & \\
\multirow{2}{*}{ Cukup } & $(61,9 \%)$ & $(0 \%)$ & $(38,1 \%)$ & & \\
\multirow{4}{*}{ Kurang } & 22 & 0 & 15 & 37 & 0,001 \\
& $(59,9 \%)$ & $(0 \%)$ & $(40,5 \%)$ & & \\
& 5 & 2 & 27 & 34 & \\
\hline
\end{tabular}

Hasil penelitian didapatkan bahwa pengukuran pengetahuan ibu tentang gizi menunjukkan 34 ibu memiliki tingkat pengetahuan kurang, $37 \mathrm{ibu}$ memiliki tingkat pengetahuan cukup dan $21 \mathrm{ibu}$ yang memiliki tingkat pengetahuan baik. Hal ini dikarenakan secara umum banyak faktor lain yang mempengaruhi pengetahuan setiap individu. Adapun menurut Notoadmojo (2010) menyebutkan bahwa faktor yang dapat mempengaruhi pengetahuan setiap individu adalah pendidikan, sumber informasi, sosial budaya, ekonomi, lingkungan dan pekerjaan. Hal ini sependapat dengan Saparudin (2017) bahwa faktor yang mempengaruhi status gizi balita salah satunya dengan tingkat pendidikan seorang ibu. Tingkat pendidikan dapat bergantung dengan pengetahuan pada manusia yang diperoleh baik secara formal maupun informal, yang mana tingkat pengetahuan dapat memberikan pengaruh pada caracara seseorang dalam memahami pengetahuan tetang gizi dan kesehatan.

Penelitian ini didapatkan tingkat pendidikan ibu yang paling banyak adalah 
tamatan SMA. Responden yang memiliki tingkat pendidikan yang tinggi cenderung memiliki tingkat pengetahuan yang baik atau cukup. Pendidikan dapat mempengaruhi proses belajar seseorang, semakin tinggi tingkat pendidikan seseorang akan mudah dalam menerima informasi yang ada. Semakin banyak informasi yang didapat maka semakin banyak pengetahuan yang didapat terrmasuk informasi kesehatan. Namun seseorang yang berpendidikan rendah belum tentu berpengetahuan rendah juga (Rakhmawati,dkk 2014). Selain itu masyarakat kurang mendapatkan informasi terkait pengetahuan tentang gizi. Hal ini terlihat dari pekerjaan ibu paling banyak adalah ibu rumah tangga (IRT) sebanyak $84,8 \%$. Namun kebanyakan ibu jarang/tidak hadir dikarenakan pekerjaan. Adapun ibu-ibu hadir bila sedang ada program gizi di posyandu seperti pembagian vitamin A yang di umumkan oleh petugas kader. Sehingga cenderung informasi-informasi tentang gizi setiap bulannya tidak dapat tersampaikan oleh petugas kesehatan bagian gizi karena ketidakhadiran ibu-ibu balita tersebut. Penelitian ini sejalan dengan penelitian Tantejo (2014) menyatakan bahwa terdapat hubungan antara pengetahuan ibu dengan status gizi balita. Penelitian tersebut menyebutkan bahwa ibu yang memiliki pengetahuan tentang gizi yang kurang cenderung memiliki balita yang berstatus gizi kurus. Hal ini karena sebagian responden peneliti tersebut memiliki pengetahuan kurang yaitu 44 responden $(46,3 \%)$ dan ini juga didukung dengan tingkat pendidikan responden yang rendah sehingga hal tersebut sangat besar berpengaruh terhadap tindakan ibu dalam memberikan makanan yang bergizi kepada balitanya (Tantejo dan Chriastianto, 2014).

Berdasarkan penelitian ini terdapat kurangnya kesadaran ibu-ibu balita untuk dapat menerima dan menerapkan informasi terkait gizi yang diberikan oleh kader atau petugas kesehatan. Pengetahuan gizi ibu diharapkan semakin meningkat kemampuan ibu dalam memilih dan merencanakan makanan dan modifikasi yang sesuai dengan syarat gizi. Serta peran petugas kesehatan untuk memperhatikan kembali ibu-ibu yang berpengetahuan kurang dengan memberikan penyuluhan atau konseling tentang gizi. Dikarenakan pengetahuan memiliki pengaruh terhadap gizi anak, yang disebabkan oleh kurangnya pengetahuan ibu tentang kebutuhan makanan dan kurangnya pendidikan yang dimiliki oleh ibu (Elvina, 2012).

Analisa bivariat hubungan keaktifan kunjungan posyandu dengan status gizi 
balita yang dilihat dari aktif $8 x /$ tahun dan tidak aktif $<8 x /$ tahun. Dilakukan dengan uji statistik Chi-square yaitu uji Pearson
Chi-square dengan tabel $3 \times 3$ dan p-value $(0,05)$. Hasil analisa tersebut dapat dilihat pada tabel dibawah ini :

Tabel 5. Hubungan keaktifan ibu balita dalam kunjungan posyandu dengan status gizi balita

\begin{tabular}{|c|c|c|c|c|c|}
\hline \multirow{2}{*}{$\begin{array}{l}\text { Variabel (Keaktifan } \\
\text { ibu balita) }\end{array}$} & \multicolumn{3}{|c|}{$\begin{array}{c}\text { Status Gizi Balita } \\
\text { (Interpretasi Indikator Pertumbuhan) }\end{array}$} & \multirow[t]{2}{*}{ Total } & \multirow[t]{2}{*}{$p$-value } \\
\hline & Normal & Akut & Kronis & & \\
\hline Aktif & $\begin{array}{c}31 \\
(49,2 \%)\end{array}$ & $\begin{array}{c}0 \\
(0 \%)\end{array}$ & $\begin{array}{c}32 \\
(50,8 \%)\end{array}$ & 63 & 0,042 \\
\hline Tidak aktif & $\begin{array}{c}9 \\
(31 \%)\end{array}$ & $\begin{array}{c}2 \\
(6,9 \%)\end{array}$ & $\begin{array}{c}18 \\
(62,1 \%) \\
\end{array}$ & 29 & \\
\hline
\end{tabular}

Pada tabel 5 menunjukkan bahwa p-value $0,042(\mathrm{p} \leq 0,05)$, artinya terdapat hubungan antara keaktifan ibu balita berkunjungan ke posyandu dengan status gizi balita. Berdasarkan hasil penelitian diketahui bahwa mayoritas responden memiliki tingkat kunjungan yang aktif dalam 1 tahun yaitu berjumlah 63 orang $(68,5 \%)$, sedangkan jumlah responden yang miliki tingkat kunjungan tidak aktif dalam 1 tahun sejumlah 29 orang $(31,5 \%)$. Hal ini disebabkan sebagian wilayah Kecamatan Teluk Segara bagian pesisir pantai memiliki tempat yang cukup strategis sehingga mudah dijangkau oleh ibu-ibu yang ikut partisipasi dalam kegiatan posyandu, pelayanan yang memadai dan sikap petugas atau kader yang selalu mengarahkan ibu untuk tetap membawa balitanya ke posyandu. Namun sebagian wilayah yang memiliki tingkat kepatuhan kunjungan ke posyandu masih kurang seperti Kelurahan Kebun Roos, Kebun Keling, dan Jitra. Hal ini dikarenakan banyak sebagian ibu hanya datang di saat adanya program gizi yang diumumkan oleh setiap kader wilayah. Sejalan dengan penelitian Sugiyarti (2014) menunjukkan bahwa adanya hubungan antara tingkat kepatuhan kunjungan posyandu dengan status gizi balita di Karangbendo Banguntapan, Bantul, Yogyakarta. Sebagian besar responden patuh dalam kunjungan poasyandu yaitu 28 orang $(70 \%)$ sedangkan yang tidak patuh sebanyak 12 orang (30\%). Berdasarkan penelitian Susanti dalam Octaviani jumlah balita yang terdapat didalam keluarga mempengaruhi kunjungan ibu ke posyandu, dimana keluarga yang memiliki jumlah balita sedikit maka ibu akan lebih sering datang 
ke posyandu serta jarak dari rumah ke posyandu sangat mempengaruhi kunjungan ibu ke posyandu .

Hasil penelitian didapat bahwa posyandu diadakan dalam 1 bulan sekali. Kehadiran ibu dilihat dari beberapa kali hadir dalam satu tahun terakhir atau dapat dilihat dibuku KMS (kartu menuju sehat). KMS adalah sebagai salah satu alat bantu pemantauan gerak pertumbuhan balita. KMS juga berfungsi untuk menilai status gizi balita. Kegiatan posyandu salah satunya adalah menimbang bayi/balita, kemudian diikuti dengan pengisian KMS berdasarkan berat badan dengan umur sehingga dapat diketahui pertumbuhan status gizi balita setiap bulannya. Sejalan dengan penelitian Mauludi (2018) menyatakan bahwa terdapat hubungan yang signifikan antara keaktifan ibu dengan status gizi. Indikator status gizi balita yang sensitif dilihat dari kenaikan berat badan. Untuk mengetahui keadaan gizi dan mengenali anak tumbuh normal dapat dilihat dari alat sederhana yang mudah digunakan di masyarakat yaitu KMS. Berdasarkan data KMS, orang tua balita dapat segara minta pertolongan kepada kader dan petugas kesehatan di posyandu apabila berdasarkan KMS anak mempunyai masalah pertumbuhan (Yogiswara, 2011).
Selain itu menurut Utami, dkk (2013), peranan ibu dalam memenuhi kebutuhan gizi balita sangat penting, dibandingkan dengan peranan para kader posyandu dan petugas kesehatan. Hal ini memicu keaktifan dari para ibu sendiri untuk aktif dalam kegiatan pemanfaatan posyandu dalam pemantauan gizi anak balita. Adapun balita yang memiliki gizi kurang tapi pemanfaatan posyandunya baik, dapat dipengaruhi oleh keadaan psikologis, kesehatan, dan sosial anak. Keadaan lingkungan dan sikap keluarga merupakan hal penting juga dalam pemenuhan gizi balita tersebut (Lanoh,dkk 2015).

Persentase status gizi kronis yang memiliki keaktifan ibu $>8 x$ setahun sebesar $50,8 \%$ sedangkan ibu yang tidak aktif $<8 \mathrm{x}$ setahun sebesar 62,1\%. Hal ini menunjukkan bahwa ketidakaktifan seorang ibu dalam kunjungan posyandu menyebabkan status gizi kronis (waktu lama). Penelitian lainnya Menurut Lestari, dkk (2012) terdapat hubungan antara tingkat kehadiran balita diposyandu dengan hasil pengukuran antropometri. Semakin tinggi tingkat kehadiran ibu balita ke posyandu maka, semakin terpantau pula status gizi balita tersebut. Ibu yang tidak aktif berkunjung ke posyandu mengakibatkan ibu kurang mendapatkan informasi mengenai pentingnya status gizi 
balita, tidak mendapat dukungan dan dorongan dari petugas kesehatan apabila ibu mempunyai permasalahan kesehatan pada balitanya. Setiap kegiatan posyandu tentu akan berpengaruh pada keadaan status gizi balita, karena salah satunya tujuan posyandu adalah memantau peningkatan status gizi masyarakat terutama anak balita. Ibu yang tidak aktif maka pemantauan pertumbuhan dan perkembangan status gizi balita tidak dapat terpantau secara optimal, karena pemantauan pertumbuhan balita dapat dipantau melalui KMS.

\section{SIMPULAN}

Ada hubungan antara pengetahuan gizi dan keaktifan ibu balita dengan status gizi balita. Bagi masyarakat perlu aktif dalam kegiatan posyandu agar mendapatkan penyuluhan dan pengetahuan gizi tentang zat-zat gizi. Bagi petugas ahli gizi di puskesmas diharapkan untuk lebih meningkatkan kinerjanya dan memberikan penyuluhan serta konsultasi melalui media leaflet kepada ibu balita tentang pengetahuan gizi dan pentingnya aktif dalam kunjungan posyandu. Bagi peneliti selanjutnya, dapat meneliti variabel penelitian tentang faktor-faktor lainnya yang dapat mempengaruhi status gizi balita seperti penyakit infeksi, asupan makan, sosial ekonomi, sanitasi lingkungan, berat badan lahir rendah (BBLR), sikap dan prilaku ibu serta kesediaan pangan.

\section{DAFTAR RUJUKAN}

Depkes RI \& WHO. 2008. Modul Pelatihan Penilaian Pertumbuhan Anak (Interpretasi Indikator Pertumbuhan).

Elvina, Helendra, Erismar. 2012. Hubungan Tingkat Pengetahuan Ibu Tentang Gizi Dengan Status Gizi Balita di Desa Sioban Kabupaten Kepulauan mentawai.

Fithria dan Azmi, N. 2015. Hubungan Pemanfaatan Posyandu Dengan Status Gizi Balita Di Kecamatan Kota Jantho. Idea Nursing Journal. Vol. VI(1), hal. 1-6.

Kemenkes RI. 2013. Laporan Akuntabilitas Kinerja Kementerian Kesehatan Tahun 2013.

Kemenkes RI. 2018. Profil Kesehatan Indonesia 2017

Lanoh M, Sarimin S, Karundeng M. Hubungan pemanfaatan posyandu dengan status Ranotana Weru Kota Manado. $J$ Keperawatan. 2015;3(2):1-7.

Lestari, P., \& Syamsianah, A. 2012. Hubungan Tingkat Kehadiran Balita di Posyandu dengan Hasil Pengukuran Antropometri Balita di Posyandu Balitaku Sayang Rw . 04 Kelurahan Jangli Kecamatan Tembalang Kota Semarang. Jurnal Gizi. 1(1), 1-9. 
Mardhiah, D., Ekayanti, I. and Setiawan, B. 2019. The Relationship Between Mother's Nutritional Knowledge Towards Fruits Vegetables Consumption and Nutritional Status of Pre School Children Kindergarten Salman Jakarta. KnE Life Sciences, 4(10), pp. 47-52. doi: 10.18502/kls.v4i10.3706.

Maria, H., Sihotang, I. dan Rahma, N. 2017. Faktor Penyebab Penurunan Kunjungan Bayi Di Posyandu Puskesmas Langsat Pekanbaru Tahun 2016. Journal Endurance. Vol.2(2): 168-177

Mauludi, N. F., Yuswatiningsih, E., \& Yosdimyati, L. 2018. Hubungan Keaktifan Ibu dalam Kegiatan Posyandu dengan Status Gizi Bayi 012 Bulan di Desa Triwung Lor Kecamatan Kademangan Probolinggo. Skripsi. http://repo.stikesicmejbg.ac.id/1308/1/143210107\%20Nur \%20Faiz\%20Maulidi\%20Artikel.pdf

Muklis, Wasliah, I. dan Utami, K. 2018. Kunjungan Ibu Dengan Status Gizi Balita Di Desa Ketapang Raya Lombok Timur. Journal Center of Research Publication in Midwifery and Nursing. Vol.2(1), hal. 47-54.

Notoatmodjo, S. 2010. Metodologi Penelitian Kesehatan. Jakarta: PT Rineka Cipta.

Octaviani, I. A., \& Ani, M. 2012. Hubungan Pengetahuan dan Perilaku Ibu Buruh Pabrik Tentang KADARZI(Keluarga Sadar Gizi) dengan Status Gizi Anak Balita(Studi di Kelurahan Pagersari, Ungaran). Journal of Nutrition College, 1(1), 46-54.

Octaviani, U., Neti, J., \& Ai, M. 2008. Hubungan Keaktifan Keluarga dalam
Kegiatan Posyandu dengan Status Gizi Balita di Desa Rancaekek Kulon Kecamatan Raancaekek, 1-16. http://pustaka.unpad.ac.id/wpcontent/ uploads/2009/10/hubungan_keaktifan _ keluarga.pdf

Puspasari, N. dan Andriani, M. 2017. Hubungan Pengetahuan Ibu tentang Gizi dan Asupan Makan Balita dengan Status Gizi Balita ( BB / U ) Usia 12-24 Bulan. Amerta Nutr. Hal. 369-378.

DOI 10.2473/amnt.v1i4.2017.369-378

Puspitasari, I. 2015. Faktor-faktor yang Mempengaruhi Partisipasi Ibu Balita Ke Posyandu Kencursari I di Dukuh Tegaltandan Desa Banguntapan Kabupaten Bantul. Skripsi. http://digilib.unisayogya.ac.id/567/1/ NASKAH\%20PUBLIKASI\%20SKR IPSI.pdf

Putri, D. S., \& Wahyono, T. Y. 2013. Faktor Langsung dan Tidak Langsung yang Berhubungan dengan Kejadian WASTING pada anak umur 6-59 bulan di indonesia tahun 2010. Media Litbangkes. 3(3), 110-121.

Rakhmawati, N.Z dan Binar P. 2014. Hubungan Pengetahuan dan sikap ibu dengan perilaku Pemberian Makanan Anak Usia 12-24 Bulan. Journal of Nutrition College. 3(1), hal.43-50.

Sakbaniyah, S., Susi, H. dan Mustika, D. 2013. Hubungan Pengetahuan Ibu Balita Dengan Kepatuhan Kunjungan Balita Ke Posyandu Di Desa Sumberejo Kecamatan Mranggen Kabupaten Demak. Jurnal Kebidanan. Vol 2(1). hal. 39-44. DOI $: \underline{10.26714 / \mathrm{jk} \cdot 2.1 .2013 . \% \mathrm{p}}$

Tantejo, B. dan Chriastianto, E. 2014. Hubungan pengetahuan ibu tentang gizi dengan status gizi balita di wilayah kerja puskesmas xiii koto 
kampar tahun 2013. JOM. 1(2), hal. $1-10$.

Tridiyawati, F., Ayu, A. dan Handoko, R. 2019. Hubungan Antara Status Sosial Ekonomi dan Pengetahuan Ibu dengan Kejadian Gizi Kurang pada Balita. Jurnal Ilmu Kesehatan Masyarakat, 8(1), hal. 20-24.

UNICEF 1990. Strategy for improved nutrition of children and women in developing countries. New york: United Nations Children's Fund

Utami, Y. R. 2013. Peranan Keaktifan Ibu Dalam Kegiatan Posyandu Dengan Status Gizi Balita Untuk Menunjang Sistem Informasi Perkembangan Balita. Jurnal Ilmiah SINUS. 12(1).
Hal 1-12.

Watania, T., Mayulu, N. dan Kawengian, S. 2016. Hubungan pengetahuan gizi ibu dengan kecukupan asupan energi anak usia 1-3 tahun di Desa Mopusi. Jurnal E-biomedik. 4(2).

Yogiswara, B. A. 2011. Hubungan Antara Tingkat Partisipasi Ibu di Posyandu Dengan Status Gizi Balita. Skripsi. http://eprints.undip.ac.id/32880/1/Bon aventura.pdf

WHO. 2018. Monitoring Health For The SDGs. Word Health Organization: World Health Statistics 